\title{
Fetomaternal Outcome of Pregnancy with COVID-19: An Observational Study in A Tertiary Care Hospital of Bangladesh
}

\author{
L CHOWDHURY $^{\mathrm{a}}$, I JAHAN ${ }^{\mathrm{b}}$, MI SHARMIN ${ }^{\mathrm{c}}, \mathrm{J} \mathrm{FERDOUSI}^{\mathrm{d}}$, T TASNIM ${ }^{\mathrm{e}}$, S NAHAR ${ }^{\mathrm{f}}$
}

\begin{abstract}
Introduction: Corona virus is a new pathogen of high contagious abilities. Pregnant women are at an increased risk due to physiologic changes in their immune, cardiopulmonary and coagulation systems. This study was designed to evaluate the fetomaternal outcome of the pregnant patients with COVID-19.
\end{abstract}

Methods: This retrospective observational study was conducted in CMH Dhaka from May 2020 to July 2020. Total 81 hospitalized pregnant patients with confirmed COVID-19 were enrolled. Relevant data were recorded in a preformed data collection sheet and analyzed by SPSS version 20

Results: Total patients were 81 with a mean age of 27 years; $49.1 \%$ were in third trimester, $83 \%$ were in $35-40$ weeks of gestation and $48 \%$ were asymptomatic. Common symptom severe cough (26\%) and fever(14\%); $7.4 \%$ patients had multiorgan failure, $81 \%$ hadlymphopenia, $7.4 \%$ patients under went chest $C T$ and had in filtrates in both lungs. Mild to moderate disease was common and $7.4 \%$ had severe disease, $3.7 \%$ needed mechanical

\section{Introduction}

Corona virus disease 2019 (COVID-19)a pandemic, continues to escalate world wide and has become a pressing global health concern. Since the

a. Brig Gen Liza Chowdhury, MBBS, MCPS, DGO, FCPS, Adviser specialist and Head of The Department, CMH Dhaka

b. Major IshratJahan, MBBS, MCPS, DGO, FCPS, Classified specialist in Obs and Gynae, CMH Dhaka

c. Lt Col Mahmuda Iffat Sharmin, MBBS, FCPS, Classified specialist in Obs and Gynae, CMH Dhaka

d. Lt Col Jannatul Ferdaushi, MBBS, DGO, FCPS, Classified specialist in Obs and Gynae, CMH Dhaka

e. Major Tafazzula Tasnim, MBBS, MCPS, DGO, FCPS, Classified specialist in Obs and Gynae, CMH Dhaka

f. Major Sabikun nahar, MBBS, DGO, Graded specialist in Obs and Gynae, CMH Dhaka

Adddress of Correspondence: Prof. Brig Gen Liza Chowdhury, Prof. and Head, Dept. of Obst. and Gynae Combined Military Hospital (CMH), Dhaka, Dhaka Cantt., Dhaka. Cell: 01819220507, E-mail: dr.lizachy@gmail.com

Received: 25 October, 2020

Accepted: 10 March, 2021 ventilation. There was a single maternal death. Most (92.6\%) patients were treated in Corona ward and $7.4 \%$ in Corona HDU and ICU. There were 3 spontaneous abortions; $64.2 \%$ delivered during the study period, $80.8 \%$ underwent a Caesarean section, $2.4 \%$ had hysterotomy, $15.1 \%$ underwent normal vaginal delivery (NVD), $15.4 \%$ patients underwent premature termination of pregnancy. Ongoing pregnancy was 26 (32.1\%).Four neonates were found COVID-positive. There was 47 livebirths, 3 intrauterine deaths (IUD) and 2 neonatal deaths. Their hospital stay was 13.1 days (SD \pm 6.37$)$.Mean interval of breastfeeding was 13.3 days ( $S D \pm 6.44)$.

Conclusion: From the study findings, it can be concluded that, COVID-19 had adverse fetomaternal outcomes. COVID-19 pandemic has exerted immense stress on health care system. With this study we can further modify our treatment strategy and reduce the load on our health system.

Key words: Corona virus, COVID-19, pregnancy, outcome.

(J Bangladesh Coll Phys Surg 2021; 39: 100-105)

DOI: https://doi.org/10.3329/jbcps.v39i2.52390

identification of the first cases in Wuhan, China, in December $2019^{1}$, the virus has spread almost to every country in the world. Local transmission of severe acute respiratory syndrome corona virus type-2 (SARS-CoV-2) is occurring in most countries $^{2}$. SARS-CoV-2 is the seventh known corona virus that infects humans and several studies support its probable zoonotic origin ${ }^{3,4}$. This is transmitted by respiratory droplets, contact with an infected person $(<2 \mathrm{~m})$ or with contaminated surfaces. There is no evidence of vertical transmission and presence of the virus in genital fluids, urine, amniotic fluid or breast milk. It belongs to the beta corona viridae, binds to angiotensin converting enzyme2 (ACE2) as the host receptor for entering the cell to cause infection ${ }^{5,6}$. Majority of infections with SARS-CoV-2 cause a mild presentation of COVID-19. Older adults and people with comorbidities, including cardiovascular and respiratory diseases and diabetes, are at increased risk of severity and death, with men potentially at higher risk than women ${ }^{7,8}$. The main findings in 
laboratory tests during early stages of the disease include lymphopenia, transaminase elevation, proteinuria, increased $\mathrm{LDH}$ and $\mathrm{C}$-reactive protein levels. Complications include severe pneumonia, acute respiratory distress syndrome, cardiac abnormalities, respiratory tract super infections, sepsis and septic shock.

Pregnant women are particularly vulnerable to infectious diseases that can cause both maternal and fetal adverse outcomes ${ }^{9-14}$. During pregnancy, immunological transformations ${ }^{15}$, physiological changes in cardio vascular, respiratory and coagulation system causes increased severity or susceptibility to infectious diseases ${ }^{16,17}$. This study evaluated fetomaternal outcomes of pregnant ladies with COVID-19.

\section{Methods}

This retrospective observational study was conducted from May 2020 to August 2020 in CMH Dhaka. Total 81 admitted pregnant patients in whom RNA of SARS CoV-2 was detected by RT PCR and their neonates were included in the study. Patients, who were treated as out-patient basis, were excluded from the study.

History, examination findings, complications and biochemical and radiological parameters of pregnancy and neonatal outcome were recorded in a preformed data collection sheet. Data were analyzed by SPSS version 20 .

\section{Results}

Total patients were 81 with a mean age of $27(\mathrm{SD} \pm 5)$ (range 19-40) years; $40.3 \%$ were primigravida (Table I), $49.1 \%$ were infected with SARS-CoV-2 in the third trimester and $32.8 \%$ had gestational age between 35-40 weeks. Common co-morbidities were pregnancy induced hypertension (PIH) (11 patients), hypothyroidism (9) and 6 patients had gestational diabetes mellitus (GDM).

Nearly half (48\%) of the patients were asymptomatic. Common symptoms were cough $(26 \%)$ and fever (14\%). Multiorgan failure was in 6\% (Table-I). Lymphopenia was common (81\%). CT scan was done in 16 patients and showed bilateral infiltrates.

Mild to moderate disease was common $(92.6 \%)$ and $7.4 \%$ had severe disease; 3 patients required mechanical ventilation (critical disease). Severe disease developed before delivery and they received mechanical ventilation after delivery. Most (92.6\%) patients were treated in Corona ward and 7.4\% patients were treated in Corona high dependency unit (HDU) and intensive care unit (ICU).

Table I. Demographic and clinical characteristics of pregnant women with COVID-19 (N=81)

\begin{tabular}{|l|l|}
\hline General characteristics & Percentage \\
\hline Mean age 27 years (range 19-40) & - \\
\hline Nulliparous & 40.3 \\
\hline Multiparous & 59.7 \\
\hline Sign and symptoms & \\
\hline Asymptomatic & 48 \\
\hline Cough & 26 \\
\hline Fever & 14 \\
\hline Shortness of breath & 2 \\
\hline Anosmia & 2 \\
\hline Multi-organ failure & 4 \\
\hline Fever, headache, severe pneumonia & 2 \\
\hline Haemoptysis & 2 \\
\hline
\end{tabular}


All (100\%) patients were treated with zinc, vit $\mathrm{C}$ and vit D. Inj. ceftriaxone, Inj. metronidazole followed by Cap. cefixime and Tab. metronidazole were used in all patients who underwent Caesarean section. Other antibiotics used were azithromycin, moxifloxacin and colistin in severe disease. In 6 patients with severe disease Inj. methyl prednisolon, Inj. remdisivir and Inj. tocilizumab were used. For thrombo prophylaxis low molecular weight heparin was used in $24(29.6 \%)$ patients and Tab. rivaroxaban in $6(7.4 \%)$ patients postnatally. Tab. ivermectin was given in $20(24.7 \%)$ patients. There was no difference in outcome between patients treated with ivermectin and not treated. During the study period, a total of 71 of 81 women ( $87.65 \%$ ) were discharged, including 5 women with severe or critical disease. There was a single maternal death.
Among the study population, there were 3 spontaneous abortions. A total 52 of 81 patients $(64.2 \%)$ delivered during the study period. Of these, 42(80.8\%) underwent a Caesarean section, 2(2.4\%) had hysterotomy and $8(15.1 \%)$ patients underwent normal vaginal delivery. Total $8(15.4 \%)$ patients under went premature termination of pregnancy. Hysterectomy was done due to HELLP syndrome and chronic hypertension with super imposed pre-eclampsia (PE). Indications of Caesarean section were history of previous Caesarean section (21), foetal distress (6), prolonged labour (3), eclampsia (3), severe PE (2), HELLP syndrome (2), unfavourable cervix (2), CPD (2),preterm labour with breech presentation (1). Ongoing pregnancy 26 $(32.09 \%)$ (Table II).

Table II. Maternal outcome of pregnant ladies with COVID-19 (N=81)

\begin{tabular}{|l|l|l|}
\hline Maternal outcome & Frequency & Percentage \\
\hline Mild to moderate disease & 75 & 92.6 \\
\hline Severe disease & 6 & 7.4 \\
\hline Delivered & 52 & 64.2 \\
\hline Dischared & 71 & 87.7 \\
\hline Ongoing pregnancy & 26 & 32.1 \\
\hline Maternal death & 1 & 1.2 \\
\hline
\end{tabular}

Testing for SARS-CoV-2 was performed on neonatal throat swabs and 4 was found positive. There were 47 livebirths, 3 intra-uterine deaths and 2 neonatal deaths. Neonatal deaths were due to extreme prematurity (Table III). Mean duration of hospital stay was $13.1(\mathrm{SD} \pm 6.4)$ (range 5-30) days. Mean interval of starting breastfeeding was $13.3(\mathrm{SD} \pm 6.44)$ (range 5-25) days.

Table III. Pregnancy and neonatal outcome of patients with COVID-19 (N=81)

\begin{tabular}{|l|l|l|}
\hline Pregnancy and neonatal outcome & Frequency & Percentage \\
\hline Delivery & 52 & 64.2 \\
\hline Normal vaginal delivery (NVD) & 8 & 15.1 \\
\hline Caesarean section & 42 & 80.8 \\
\hline Hysterotomy & 2 & 2.4 \\
\hline Abortion & 3 & 3.7 \\
\hline Live birth & 47 & 90.4 \\
\hline Preterm birth & 8 & 15.4 \\
\hline Neonatal death & 2 & 3.8 \\
\hline Neonatal COVID infection & 4 & 7.6 \\
\hline
\end{tabular}




\section{Discussion}

Coronavirus is a new pathogen of high contagious abilities. Pregnant women are at an increased risk due to physiologic changes in their immune, cardiopulmonary and coagulation systems. But several authors suggested that pregnancy did not aggravate the symptoms or CT features of COVID-19 pneumonia ${ }^{18}$. A previous review including 108 infected pregnant women in the third trimester described fever (68\%) and cough (34\%) as the most frequent symptoms of COVID-19 and elevated C-reactive protein (70\%) and lymphopenia $(59 \%)$ as the most commonly altered maternal laboratory parameters ${ }^{19}$. In our study $48 \%$ of patients were asymptomatic. Cough (26\%) and fever (14\%) were the most common symptoms. CT scan was done in only $7.6 \%$ of patients and $81 \%$ had lymphopenia.

\section{Maternal and fetaloutcomes}

A vast majority of available publications refers to Chinese pregnant women. In a case series including three pregnant women infected by SARS-CoV-2, one of the infants was born preterm with low birth weight $(\mathrm{LBW})^{20}$. Other publication presented the case of a 30-week pregnant woman with COVID-19 that gave birth to a LBW but healthy baby ${ }^{21}$. In our study prematurity was found in $15.8 \%$ of cases.

Liu et al. presented 13 pregnant women infected with SARS-CoV-2, two with less than 28 weeks of gestation and 11 in the third trimester ${ }^{22}$. Three patients improved after hospitalization, were discharged from the hospital and had an uncomplicated pregnancy. The other ten patient sunder went Caesarean section, of which five were emergency sections because of fetal distress $(n=3)$, premature rupture of membranes (PROM) $(n=1)$ and stillbirth $(n=1)$. Six patient shad preterm labour from 32 to 36 weeks of gestation. The condition of one of the mothers deteriorated during hospitalization, requiring ICU admission with intubation and mechanical ventilation. This woman presented with multiple organ dysfunction syndrome (MODS) that comprised of acute respiratory distress syndrome (ARDS), acute hepatic failure, acute renal failure and septic shock and was under extracorporeal membrane oxygenation at the time of the study ${ }^{22}$. In our study, $49.1 \%$ patients were infected in $3^{\text {rd }}$ trimester, 52 patients were delivered during study period, 6 patients developed severe disease with multiorgan failure and were treated in ICU, 3 of them required mechanical ventilation and one patient died.

Chen $\mathrm{H}$ et al. reported two cases of fetal distress, four cases of preterm delivery (one mother with pre-eclampsia, one case of PROM and two with previous history of Caesarean sections or stillbirth) and two of LBW (the mother with preeclampsia and the case of PROM) among nine pregnant women infected with COVID-19 ${ }^{23}$. Chen R. et al. included 17 infected pregnant women, three of the neonates were prematurely born ${ }^{24}$. One case of new born died due to endouterine asphyxia was reported in a critically ill pregnant woman with SARS-CoV-2 (who developed severe acute respiratory distress syndrome, multiple organ dysfunction syndrome, and septic shock $)^{25}$. In our study, fetal distress was found in 6 cases, IUD in 3 case and premature termination of pregnancy in 8 cases.

Zhu H. et al. found several adverse pregnancy outcomes among nine infected women (clinical symptoms beginning before delivery in four cases, on the day of delivery in two mothers, and after delivery in other three) ${ }^{26}, 6$ were born premature, 2 were small for gestational age (SGA) infants.

A second case-control study by Li N. et al. compared 16 pregnant women with confirmed COVID-19 pneumonia and 18 suspected cases, all with mild symptoms who were admitted to labour in the third trimester, with two cohorts of 121 age-matched control pregnant women each (one from 2019 and one from 2020 $)^{27}$. Around $70 \%$ of the two cases groups presented other maternal complications (mostly GDM, gestational hypertension and hypothyroidism), a percentage significantly higher than in the control groups(33\%). Three confirmed cases $(18.8 \%$, two caused by PROM and one by placental bleeding) and three suspected cases (16.7\%, one due to gestational hypertension/ preeclampsia and one due to placenta praevia) deliver prematurely, compared with a $5.8 \%$ of the controls. In our study most common comorbidities were $\operatorname{PIH}(13.58 \%)$, hypothyroidism(11.11\%) and $\operatorname{GDM}(7.40 \%)$.

\section{Delivery}

In a prospective cohort study, the majority had Caesarean deliveries, 16/19 (68.4\%), 13/16 (81\%) had an emergency C-sections while, 3/16 (11.8\%) had an elective $\mathrm{C}$-sections ${ }^{28}$. Indications for the C-sections included pathological CTG, failure to progress of labour, PROM including subsequent 
unsuccessful induction of labour, maternal request and severe sepsis. Two case-control studies have been conducted in China. Zhang L. et al. compared the pregnancy outcomes of 16 women with COVID-19(one severe case)and 45 non-infected women, all delivering by Caesarean section ${ }^{29}$. Researchers did not observe significant differences in the intra-operative blood loss. In our study, $64.1 \%$ patients underwent Caesarean section and 15.14\% patients underwent NVD.

\section{Neonatal outcome}

Zhu H. et al. found six newborns had a Pediatric Critical Illness Score (PCIS) lower than 90 and showed clinical symptoms including shortness of breath $(n=6)$, fever $(n=2)$, thrombocytopenia accompanied by abnormal liver function $(n=2)$, rapid heart rate $(n=1)$ and vomiting $(n=1)$. Four neonates presented with gastrointestinal symptoms including bloating, refusing milk, feeding intolerance and gastric bleeding and seven showed radiography abnormalities (infections, $\mathrm{n}=4$; neonatal respiratory distress syndrome, $\mathrm{n}=2$; and pneumothorax, $\mathrm{n}=1$ ). One infant presented multiple organ failure, refractory shock and disseminated intravascular coagulation at day 8 after delivery, received a transfusion and died on day $9^{26}$. In our study only 4 neonates were found RT-PCR positive. There were 2 neonatal deaths due to extreme prematurity. Rest of them were doing well.

\section{Conclusion}

Our study findings suggest adverse fetomaternal outcomes of COVID-19. Although pregnant women do not seem to present an increased susceptibility to COVID-19 or more severe complications than non-pregnant adults, the available studies suggest that they may be at risk of adverse pregnancy outcomes, mostly preterm delivery, fetal distress, respiratory symptoms and LBW in the newborns. Further research is urgently needed to understand the real effect of COVID-19 on pregnant women and neonates, and to guide the most appropriate recommendations for obstetricians. Only an integrated multi-angle assessment of the current knowledge about viral characteristics, epidemiology, disease immunopathology, potential preventive and

therapeutic strategies, together with clinical observations, will help to understand the exact impact of COVID-19 infection during pregnancy.

\section{References}

1. Zhu N, Zhang D, Wang W, Li X, Yang B, Song J, Zhao X, Huang B, Shi W, Lu R, Niu P. A novel coronavirus from patients with pneumonia in China, 2019. New England journal of medicine. 2020 Jan 24.

2. World Health Organization: Coronavirus Disease 2019 (COVID-19) Situation Report-78. 2020.

3. Andersen KG, Rambaut A, Lipkin WI, Holmes EC, Garry RF. The proximal origin of SARS-CoV-2. Nature medicine. 2020 Apr;26(4):450-2.

4. Zhang T, Wu Q, Zhang Z. Probable Pangolin Origin of SARS-CoV-2 Associated with the COVID-19 Outbreak. Curr Biol. 2020; 30(7): 1346-1351.e2.

5. Zhou P, Yang XL, Wang XG, Hu B, Zhang L, Zhang W, Si HR, Zhu Y, Li B, Huang CL, Chen HD. A pneumonia outbreak associated with a new coronavirus of probable bat origin. nature. 2020 Mar;579(7798):270-3.

6. Letko M, Marzi A, Munster V. Functional assessment of cell entry and receptor usage for SARS-CoV-2 and other lineage B betacoronaviruses. Nat Microbiol. 2020; 5(4): 562-569.

7. $\mathrm{Wu} \mathrm{Z}$, McGoogan JM. Characteristics of and important lessons from the coronavirus disease 2019 (COVID-19) outbreak in China: summary of a report of 72314 cases from the Chinese Center for Disease Control and Prevention. Jama. 2020 Apr 7;323(13):1239-42.

8. IstitutoSuperiore di Sanità. Report about the Characteristics of Death Patients Positive to COVID-19 in Italy (Based on Data Updated on 17th March 2020).

9. He J, Liu ZW, Lu YP, Li TY, Liang XJ, Arck PC, Huang SM, Hocher B, Chen YP. A systematic review and meta-analysis of influenza a virus infection during pregnancy associated with an increased risk for stillbirth and low birth weight. Kidney and Blood Pressure Research. 2017;42(2):232-43.

10. Mertz D, Geraci J, Winkup J, Gessner BD, Ortiz JR, Loeb M. Pregnancy as a risk factor for severe outcomes from influenza virus infection: a systematic review and meta-analysis of observational studies. Vaccine. 2017 Jan 23;35(4):521-8.

11. Bergløv A, Hallager S, Weis N. Hepatitis E during pregnancy:Maternal and foetal case-fatality rates and adverse outcomes-A systematic review. JViral Hepat.2019; 26(11): 1240-1248.

12. Shi TL, Huang LJ, Xiong YQ, Zhong YY, Yang JJ, Fu T, Lei XF, Chen Q. The risk of herpes simplex virus and human cytomegalovirus infection during pregnancy upon adverse pregnancy outcomes: A meta-analysis. Journal of Clinical Virology. 2018 Jul 1;104:48-55. 
13. Niyibizi J, Zanré N, Mayrand $\mathrm{MH}$, Trottier $\mathrm{H}$. Association between maternal Human Papillomavirus infection and adverse pregnancy outcomes: systematic review and meta-analysis. The Journal of infectious diseases. 2020 Jun 11;221(12):1925-37.

14. Thompson JM, Eick SM, Dailey C, Dale AP, Mehta M, Nair A, Cordero JF, Welton M. Relationship between pregnancy-associated malaria and adverse pregnancy outcomes: a systematic review and meta-analysis. Journal of tropical pediatrics. 2020 Jun;66(3):327-38.

15. Silasi M, Cardenas I, Kwon JY, Racicot K, Aldo P, Mor G. Viral infections during pregnancy. American journal of reproductive immunology. 2015 Mar;73(3):199-213.

16. Kourtis AP, Read JS, Jamieson DJ.Pregnancy and Infection. $N$ Engl J Med. 2014; 370(23): 2211-2218.

17. Hause AM, Avadhanula V, Maccato ML, Pinell PM, Bond N, Santarcangelo P, Ferlic-Stark L, Munoz FM, Piedra PA. A cross-sectional surveillance study of the frequency and etiology of acute respiratory illness among pregnant women. The Journal of infectious diseases. 2018 Jul 13;218(4):528-35.

18. Wong SF, Chow KM, Leung TN, Ng WF, Ng TK, Shek CC, Ng PC, Lam PW, Ho LC, To WW, Lai ST. Pregnancy and perinatal outcomes of women with severe acute respiratory syndrome. American journal of obstetrics and gynecology. 2004 Jul 1;191(1):292-7.

19. Zaigham M, Andersson O. Maternal and Perinatal Outcomes with COVID-19:a systematic review of 108 pregnancies. ActaObstetGynecol Scand. 2020.

20. Chen S, Huang B, Luo DJ, Li X, Yang F, Zhao Y, Nie $X$, Huang BX. Pregnancy with new coronavirus infection: clinical characteristics and placental pathological analysis of three cases. Zhonghua bing li xue za zhi= Chinese journal of pathology. 2020 Mar $1 ; 49(5): 418-23$.

21. Wang X, Zhou Z, Zhang J, Zhu F, Tang Y, Shen X. A case of 2019 Novel Coronavirus in a pregnant woman with preterm delivery. Clinical infectious diseases. 2020 Feb 28.
22. Liu $\mathrm{Y}$, Chen $\mathrm{H}$, Tang $\mathrm{K}$, Guo $\mathrm{Y}$. Clinical manifestations and outcome of SARS-CoV-2 infection during pregnancy. The Journal of infection. 2020 Mar 4.

23. Chen H, Guo J, Wang C, Luo F, Yu X, Zhang W, Li J, Zhao D, Xu D, Gong Q, Liao J. Clinical characteristics and intrauterine vertical transmission potential of COVID-19 infection in nine pregnant women: a retrospective review of medical records. The lancet. 2020 Mar 7;395(10226):809-15.

24. Chen R, Zhang Y, Huang L, Cheng BH, Xia ZY, Meng QT. Safety and efficacy of different anesthetic regimens for parturients with COVID-19 undergoing Cesarean delivery: a case series of 17 patients. Canadian Journal of Anesthesia/Journal canadien d'anesthésie. 2020 Jun;67(6):655-63.

25. Zhang B, Liu S, Tan T, Huang W, Dong Y, Chen L, Chen Q, Zhang L, Zhong Q, Zhang X, Zou Y. Treatment with convalescent plasma for critically ill patients with severe acute respiratory syndrome coronavirus 2 infection. Chest. 2020 Jul 1;158(1):e9-13

26. Zhu H, Wang L, Fang C, Peng S, Zhang L, Chang G, Xia S, Zhou W. Clinical analysis of 10 neonates born to mothers with 2019-nCoV pneumonia. Translational pediatrics. $2020 \mathrm{Feb}$;9(1):51.

27. Duran $\mathrm{P}$, Berman $\mathrm{S}$, Niermeyer S, Jaenisch T, Forster T, Gomez Ponce de Leon R, De Mucio B, Serruya S. COVID-19 and newborn health: systematic review. Revista Panamericana de Salud Pública. 2020 May 29;44:e54.

28. Maternal COVID-19 infection, clinical characteristics, pregnancy, and neonatal outcome: A prospective cohort study.doi: 10.1016/j.ejogrb.2020.07.008

29. Zhang L, Jiang Y, Wei M, Cheng BH, Zhou XC, Li J, Tian JH, Dong L, Hu RH. Analysis of the pregnancy outcomes in pregnant women with COVID-19 in Hubei Province. Zhonghua fu chan ke za zhi. 2020 Mar 7;55(3):166-71. 